Nalar: Jurnal Peradaban dan Pemikiran Islam

Vol. 3, No. 1, Juni 2019

\title{
Perjuangan Badiuzzaman Said Nursi dalam Membendung Arus Sekularisasi di Turki
}

\author{
Ilyas Fahmi Ramadlani \\ Sekolah Tinggi Agama Islam Sunan Pandanaran \\ ramadlani15@gmail.com
}

\begin{tabular}{|c|c|}
\hline \multicolumn{2}{|r|}{ Abstrak } \\
\hline Article History & Badiurzaman Said Nursi bidup dalam situasi Islam yang sulit, yakni \\
\hline Received : 22-3-2019 & ketika Turki Utsmani dan beberapa kerajaan Islam lainnya mengalami \\
\hline Revised : 29-5-2019 & kemunduran. Menelusuri sejarah hidup Badiuzzaman Said Nursi tidak \\
\hline Accepted: 30-6-2019 & akan terlepas dari konteks keadaan negara saat dia tinggal. Hal itu \\
\hline Kata Kunci : & disebabkan karena pemikirannya merupakan produk atas kenyataan \\
\hline Badiurzaman Said & Turki yang dipengarubi budaya Barat. Akbir masa pemerintahan Turki \\
\hline Nursi, & Utsmani manjadi tanda awal pertemuan antara kaum muslimin dan \\
\hline Sekularisasi & perdaban Barat. Tatkala Mustafa Kemal Attaturk menduduki \\
\hline Turki Utsmani. & pemerintahan Turki dan menggantinya menjadi Republik Turki, Islam \\
\hline & lantaran kebijakan-kebijake \\
\hline & diadopsi dari budaya Barat. Situasi ini kemudian mendorong Badiuzzaman \\
\hline & Said Nursi untuk berjuang melakukan perubaban sikap dan pemikiran \\
\hline & $\begin{array}{l}\text { umat muslim dengan jalan dakwah secara kultural yang diaplikasikan } \\
\text { dalam bentuk ceramah dan tulisan. Dengan mengqunakan pendekatan }\end{array}$ \\
\hline & sosio-bistoris, artikel ini bertujuan untuk menggali perjuangan \\
\hline & $\begin{array}{l}\text { Badiurzaman Said Nursi dalam membendung arus radikalisasi, mengingat } \\
\text { saat itu keberadaan Islam terancam hilang dari bumi Turki. }\end{array}$ \\
\hline
\end{tabular}

\section{Pendahuluan}

Dunia Islam memiliki sejarah pemikiran yang bergelimang. Said Nursi adalah salah satu dari beberapa khazanah pemikiran Islam itu. Said Nursi lahir pada masa yang sangat kritis, tatkala Turki Utsmani mengalami kemunduran dan sebagian negara Islam dijajah oleh Barat. Sementara para cendekiawan dan pejuang Turki Utsmani berada di bawah pengaruh Barat. Said Nursi mengalami masa pemerintahan konstitusional Turki Utsmani, pertai tunggal Republik Turki dan masa politik partai. Kondisi umat muslim yang menyedihkan dan pengalaman yang luar biasa mematangkan Said Nursi lantaran harus mencari beragam solusi untuk menghadapi tantangan Barat itu.

Pada awal Said Nursi berkiprah di konstitusi Turki Utsmani, dia menaruh harapan besar bahwa Turki Utsmani mampu bangkit. Said Nursi pernah menyampaikan proyek gagasannya kepada sultan untuk memperbaiki konstitusi Utsmani, tetapi dia melihat dan menyadari bahwa para cendekiawan elite Turki Utsmani kehilangan kepercayaan lantaran terpesona dengan peradaban Barat yang berkembang pesat di bidang ilmu pengetahuan dan teknologi. Oleh sebab itu, solusi terbaik bagi para cendekiawan Turki Utsmani adalah bertaklid buta kepada Barat tanpa berpikir panjang terhadap pelbagai dampaknya.

Dalam kondisi ini, Said Nursi ingin menyelamatkan dan memperkokoh keimanan umat muslim Turki dengan cara menjadikan alquran dan hadis sebagai pijakan utama sehingga membuahkan pandangan yang lebih universal atau bersifat inklusivistik, sebab menurut Said Nursi siapa pun bisa menimba kebajikan dari kedua sumber tersebut. Said Nursi 
Nalar: Jurnal Peradaban dan Pemikiran Islam

Vol. 3, No. 1, Juni 2019

memfokuskan dirinya pada persoalan Iman dan beranggapan bahwa Iman adalah sumber energi dan kekuatan paling besar bagi dunia Islam. Jika umat muslim dan dunia Islam selamat, hal itu hanya mungkin dengan Iman sebagai energi perubahan yang harus mendominasi umat muslim.

Tentu tidak benar bila dikatakan bahwa Said Nursi meremehkan politik bahkan menganggapnya sebagai sesuatu yang membahayakan. Pendapat ini juga diperkuat Habiburrahman El Shirazy (El Shirazy, 2014: 456-457) dengan pernyataannya bahwa satusatunya pilihan Said Nursi ketika menghadapi pemerintahan sekuler Mustafa Kemal Attaturk adalah berpolitik melawan segala bentuk usaha yang menjauhkan umat dari alquran dan Islam. Said Nursi memiliki pandangan bahwa dunia Islam membutuhkan langkah yang baru dengan menguatkan energi kekuatan Islam yang berasal dari iman, pemikiran, dan ilmu. Sehingga Said Nursi membutuhkan langkah berbeda dalam mengatasi permasalahan umat muslim di Turki ketika Attaturk mulai berkuasa.

Hal ini kemudian mendorong Said Nursi untuk melakukan perubahan dalam sikap dan pemikiran dengan jalan dakwah secara kultural yang diaplikasikan dalam bentuk ceramah dan tulisan yang dapat mengokohkan kembali bangunan keimanan umat dengan ajaran alquran yang terangkum dalam risalah nur. Untuk itu, perlu dilakukan pengkajian lebih mendalam mengenai bagaimana perjuangan Said Nursi dalam membendung arus sekularisasi yang sangat merugikan umat muslim di Turki (Vahide, 2007: xviii).

\section{Biografi Badiuzzaman Said Nursi}

Menelusuri sejarah hidup Badiuzzaman Said Nursi tidak akan terlepas dari konteks keadaan negara saat dia menetap. Perihal itu karena pemikirannya merupakan produk atas kenyataan Turki yang terbelenggu pengaruh Barat saat itu. Pertemuan antara kaum muslimin dan peradaban Barat, masuknya Eropanisasi, dan terkikisnya keislaman, sampai akhir masa dinasti Turki Utsmani dan perubahannya menjadi Republik Turki. Secara garis besar kehidupan ulama' Turki ini terbagi dalam dua fase.

Fase pertama adalah fase mudanya, saat mencari ilmu dan keikutsertaannya mempertahankan Islam melalui pemerintahan akhir Turki Utsmani. Fase kedua adalah saat di mana Said Nursi membendung arus sekularisasi di Turki dan di mana saat dia kembali diangkat menjadi penasihat pemerintahan sama seperti saat pemerintahan Turki Utsmani (Salih, 2003: 50).

Said Nursi salah satu pemikir Islam kontemporer yang cemerlang. Dia dilahirkan pada 1293 H/1876 M. dengan nama Said bin Mirza. Said Nursi berasal dari desa Nurs, yaitu salah satu perkampungan Khaizan di wilayah Bitlis yang terletak di sebelah Timur Anatolia. Sebuah perkampungan yang indah karena letak geografisnya dikelilingi gunung-gunung dan damai karena dihuni penduduk yang religius. Ayahnya bernama Mirza, terkenal sebagai seorang sufi pendukung tarekat Khalidiyyah. Ibunya bernama Nuriye seorang perempuan yang tidak pernah meninggalkan sembahyang tahajjud (selain dalam keadaan uzur) dan selalu memastikan dirinya dalam keadaan berwudhu ketika hendak menyusui anak-anaknya (Salih, 2003: 8). Menurut Sukran Vahide (Vahide, 2007: 4), Said Nursi merupakan anak keempat dari kedua mempelai yang berasal dari suku Kurdi, sehingga dapat ditegaskan bahwa Said Nursi adalah keturunan asli suku Kurdi.

Said Nursi mendapat didikan pertama dari keluarganya sendiri. Sebagaimana putraputri ulama pada masanya, Said Nursi dipengaruhi oleh didikan karakter orang tuanya. Ketegasan ayahnya membentuk sifat disiplin dan istikamah, sedangkan kelembutan dan keibuan Nuriye menanamkan sifat kasih sayang ke dalam diri Said Nursi (Vahide, 2007: 3). 
Nalar: Jurnal Peradaban dan Pemikiran Islam

Vol. 3, No. 1, Juni 2019

Said Nursi mulai mencari ilmu sejak umur sembilan tahun. Kegemarannya dalam menuntut ilmu membuatnya mudah menguasai banyak ilmu pengetahuan. Hal ini kemudian melatarbelakangi keseringannya berpindah belajar dari suatu tempat ke tempat yang lain. Adapun tempat yang pernah disinggahi untuk menuntut ilmu adalah Tagh, Birmis, Nurshin, Arvas, Muks, Gewash, dan Buyazet. Di berbagai tempat ini, Said Nursi bertemu dengan guruguru yang mempengaruhinya dalam keilmuan. Di antaranya adalah: Shyakh Muhammad Amin Afandi, Shyakh Sayyid Nur Muhammad, Shyakh Muhammad al-Jalali, Shyakh Muhammad al-Kafrawi, Shyakh Abd al-Rahman, Shyakh Fahim, Mulla Abdullah, Mulla Ali al-Sawran, dan Mulla Fathullah (Vahide, 2007: 30).

Selain mengasah ilmu agama melalui gurunya, Said Nursi juga sering mengasah ilmunya dengan mengulang kembali pelajaran yang sudah dipelajarinya. Said Nursi juga sering belajar dengan cara otodidak terhadap pelajaran yang mungkin bisa dipahami. Oleh karena itu, tidak mengherankan jika dia telah dijuluki molla sejak usia 14 tahun karena mampu menyelesaikan pelajaran dalam jangka enam bulan yang biasanya hanya dapat ditempuh seseorang setelah mempelajarinya sekitar lima belas sampai dua puluh tahun (Khamami, 2015: 4). Di sisi lain, Said Nursi juga memiliki kebiasaan hadir dalam majlis ilmu dari satu tempat ketempat lainnya, sehingga kebiasaan ini juga membuatnya lebih berkembang dari teman belajar lainnya. Ketika berumur 16 tahun, Said Nursi hafal dan menguasai kitab-kitab turas (kuning) seperti Jam'u al-Jawami', Sharh al-Mawafiq, Risalah as-Syamsyiah, dan beberapa kitab turas lainnya. Bahkan suatu ketika keilmuan Said Nursi pernah diuji oleh ratusan ulama Turki di majelis umum yang dihadiri ribuan jamaah di masjid Kota Siirt. Said Nursi diberi pertanyaan-pertanyaan rumit, namun semua pertanyaan dijawab dengan tuntas dan tepat, dan membuat semua yang hadir dalam majlis takjub kepadanya (Habiburrahman, 2014: 202).

Tidak hanya di ilmu agama, Said Nursi juga mampu menguasai ilmu-ilmu modern seperti sejarah, geografi, matematika, geologi, fisika, kimia, astronomi, dan filsafat. Perihal ini kemudian yang melatarbelakangi Said Nursi diberi gelar Badiuzzaman sebagai bentuk pengakuan ulama dan para ilmuan di Turki terhadap kegemilangannya dalam menguasai segala macam keilmuan (Astuti, 2018: 21). Dengan kedalaman ilmu yang beliau capai, kemudian Badiuzzaman Said Nursi berkeinginan untuk mengajarkan, mengembangkan, dan memadukan antara ilmu agama dengan ilmu-ilmu modern kepada umat Islam khususnya di Turki (Vahide, 2007: 32). Menurut Said Nursi, sangat perlu diadakan pengintegritasan antara ilmu agama dan modern karena ilmu agama adalah cahaya hati dan ilmu-ilmu modern adalah cahaya akal yang keduanya saling melengkapi.

Setelah demikian, Said Nursi benar-benar berusaha untuk merealisasikan cita-citanya untuk memadukan antara ilmu modern dan agama. Said Nursi menilai bahwa kemunduran Islam saat itu karena umat Islam alergi dengan kemajuan ilmu modern hingga akhirnya umat muslim terjauhkan dari kemajuan zaman. Pandangan ini kemudian mendorong Said Nursi untuk mendirikan sebuah sekolah dengan sistem yang mengintegrasikan antara keilmuan Islam dengan ilmu modern. Dengan usahanya, Said Nursi meminta persetujuan sultan Abdul Hamid (tahun 1896 dan 1907 M.) agar diperkenankan memadukan antara ilmu modern dan agama di suatu Universitas di Anatolia. Namun keinginan tersebut tidak dikabulkan Sultan Abdul Hamid (Vahide, 2007: 25).

Said Nursi hidup dan berkembang di akhir pemerintahan dinasti Turki Utsmani. Pada masa ini, Said Nursi mengalami kesulitan untuk menyalurkan pengetahuannya kepada masyarakat Turki. Faktor yang paling mendasari cita-citanya terhadap umat Islam di Turki adalah mundurnya dinasti Turki Utsmani. Kepemerintahannya telah dipengaruhi dan fanatik terhadap ilmuan Barat sehingga dapat merusak kepemimpinan dan sistem Islam di Turki. Keadaan Turki pada saat itu benar-benar telah kacau, Islam yang berabad tahun tertanam di 
Nalar: Jurnal Peradaban dan Pemikiran Islam

Vol. 3, No. 1, Juni 2019

sana secara keseluruhan mampu dirombak dengan masuknya budaya Barat.

Said Nursi tetap melawan dan menolak terhadap masuknya penjajahan dunia Barat. Titimangsa 1899 M, Said Nursi ikut berperang melawan penjajah Inggris yang ingin melenyapkan alquran di Turki. Kemudian pada 1908-1912 M., Said Nursi berusaha mempertahankan tegaknya Syariat Islam. Namun usahanya tetap gagal hingga dinasti Turki Utsmani lenyap diganti dengan sistem kepemerintahan Republik Turki oleh Mustafa Kemal Attaturk. ${ }^{1}$

Sejak kepemimpinan Mustafa Kemal Attaturk, Said Nursi sering mendapat perlakuan yang tidak baik karena dinilai tidak sejalan dengan keinginan penguasa pada saat itu. Namun Said Nursi tetap berusaha dengan pelbagai cara, ajaran-ajaran Islam tetap dia dakwahkan meski di pengasingan dan penjara. Dengan cara berceramah dan menulis kitab yang dikenal dengan rislah nur, Said Nursi bertekad menyadarkan masyarakat agar tidak tergerus oleh budaya Barat. Dalam menyebarkan risalah nur kepada para murid dan umat muslim yang ada di Turki, Said Nursi bekerja sama dengan para murid-muridnya. Risalah nur disalin sebanyakbanyaknya dengan tulisan manual dan disebarkan ke berbagai penjuru dalam bentuk surat. Usaha ini terus dilakukan oleh Said Nursi dan muridnya meski disiksa, diasingkan, dan dipenjara, hingga akhirnya pemerintahan Mustafa Kemal diambil alih Adnan Menderes di bawah Partai Demokrat (Arifin, 2003: 57-63).

Usaha Said Nursi tidak sia-sia, setelah berjuang melawan kezaliman, melewati masa keruntuhan Islam di Turki, kekerasan tentara Republik Tukri, dan pengasingan. Akhirnya pemerintahan Kemalis dapat diambil alih Partai Demokrat. Pada saat itu juga, tulisan risalah nur semakin banyak tersebar dan diterima penduduk Turki lantaran usaha Said Nursi dan murid-muridnya melalui dukungan pemerintah. Selanjutnya setelah dinasti Kemal Attaturk musnah, Said Nursi tinggal bersama murid-murid dekatnya untuk membimbing dan mengajar metode dakwah risalah nur sebelum kemudian Said Nursi tutup usia pada 23 Maret 1960 M., bertepatan dengan 25 Ramadlan 1379 H. Said Nursi dikebumikan di Ulu Jami' pada 24 Maret 1960 M. (Vahide, 2007: 25).

\section{Sejarah Akhir Pemerintahan Turki dan Munculnya Arus Sekularisasi}

Raja pertama kerajaan Turki Utsmani bernama Usman yang memerintah antara 12901326 M. Kurang lebihnya pada periode pertama, kerajaan Turki Utsmani lebih condong melakukan perlebaran kekuasaan serta memantapkan keamanan dalam negeri. Kerajaan Turki Utsmani baru mangalami perkembangan pesat serta ekspansi besar-besaran ketika masuk periode kedua. Salah satu aspek yang tidak dapat dilepaskan dari perannya dalam kemajuan Turki Utsmani adalah aspek keagamaan. Keagamaan memiliki peranan penting dalam kehidupan sosial dan politik. Waktu itu pihak penguasa sangat terikat dengan syariat Islam sehingga fatwa ulama menjadi hukum yang berlaku. Mufti sebagi pejabat urusan agama

${ }^{1}$ Sejak 3 Maret 1916 hingga Juni 1918, Said Nursi menjadi tawanan pasukan Rusia. Dia harus berpindah dari satu kota ke kota lain hingga berada di Kosturma, Rusia barat daya. Di sana, di sebuah masjid kecil yang biasa Said Nursi gunakan untuk beribadah selama pengasingan itu, dia merenungkan kehidupannya. Itulah titik balik kesadarannya yang kemudian melahirkan perubahan terhadap dirinya. Disaat Turki telah dipimpin oleh Mustafa Kemal Attaturk Said Nursi tidak memberontak, bahkan Said Nursi mendukung gerakan nasional dengan catatan menaruh harapan besar masa depan Islam kepada mereka. Dia yang saat itu berada di Istanbul mendapatkan beberapa kali undangan untuk datang ke Ankara untuk memberikan dukungan atas pemerintahan Ankara. Akhirnya, pada 9 November 1922 (45 th) Said Nursi datang ke Ankara dan memberikan sambutan di hadapan Majelis. Said Nursi memberikan selamat kepada Gerakan Nasional atas keberhasilannya memperjuangkan kemerdekaan, dan mengingatkan agar tetap mengutamakan pembentukan konstitusi yang sesuai dengan syariah. Namun usahanya itu ternyata mendapatkan pertentangan dari Mustafa Kemal. Lihat Erik J. Zurcher, Sejarah Modern Turki (Jakarta: Gramedia, 2003), hlm. 228-232. 
Nalar: Jurnal Peradaban dan Pemikiran Islam

Vol. 3, No. 1, Juni 2019

tertinggi berwenang memberi fatwa resmi terhadap problem keagamaan (Mughni, 1997: 93).

Dari sisi lain perkembangan pesat yang diperoleh, timbul bibit-bibit kemunduran dinasti Turki Utsmani. Kemunduran dinasti Turki Utsmani ini ditandai dengan kekalahankekalahan dalam pertempuran pasukan Kristen Barat. Tahun 1702 diadakan perjanjian Carlowitz dan dalam perjanjian itu, Turki Utsmani harus rela menyerahkan wilayah Hongaria, Transilvania, Morea, Albania, Pedolia, dan Azzof (Zurcher, 2003: 30-38 ). Pada abad ke-17 dan ke-18, dinasti Turki Utsmani diperintah oleh sekitar lima orang sultan, tetapi tidak ada seseorang pun yang dapat mengatasi tantangan besar yang menghantam Turki Utsmani, terutama terhadap segala tantangan yang berasal dari Eropa. Dengan ini, secara umum kemunduran Turki Utsmani disebabkan sistem birokrasi yang hanya terpaku kepada kemampuan sultan untuk mengelolanya.

Pergeseran moral yang ditunjukan sultan-sultan kemudian dijadikan sebagi salah satu pemicu munculnya delegitimas yang menumbuhkan pemberontakan menentang kepemimpinan dan kekuasaan sultan (Zurcher, 2003: 30-38). Konflik internal yang terjadi dalam Dinasti Utsmani, memecah belah kaum muslim sehingga bangsa-bangsa yang tunduk dibawah pemerintahan Turki Utsmani, mulai menyadari kelemahan dinasti tersebut dan ingin melepaskan diri dari pemerintahan dinasti Turki Utsmani (Ajid Thohir, 2009: 193).

Kemudian muncul sosok Mustafa Kemal Attaturk dari kalangan militer yang ingin menonjolkan dan menjalankan sistem Negara di Turki. Dia berkata bahwa kedaulatan berada di tangan rakyat. Dalam melaksanakan aksi, Kemal mengawali gerakannya dengan menanamkan semangat Nasionalisme kepada masyarakat Turki. Upaya ini berhasil dan Mustafa Kemal Attaturk terpilih menjadi presiden pertama Turki. Karena dia terpengaruh oleh pemikiran Barat, Kemal ingin melenyapkan kekhilafaan serta menghapuskan jejak dinasti Turki Utsmani dan menggantinya dengan sistem demokrasi Barat (Nasution, 1996: 192). Sejak itu arah kebijakan pemerintah bergeser ke arah prinsip sekularisme dan libelarisme (Husaini, 2005: 272).

Pada awal pemerintahannya Mustafa Kemal mengesahkan undang-undang Unifiksi dan sekularisasi pendidikan pada 3 Maret 1924. Kemudian pada 30 Mei 1924 kementerian wakaf dihapuskan dari sistem kepemerintahan Turki karena dianggap mempunyai unsur agama dan menyalahi prinsip sekularisme. Dalam tahun ini pula masjid-masjid dilarang untuk dioperasionalkan kecuali satu masjid yaitu Masjid Abu Ayyub al-Anshari, bahkan Masjid Haghia Sophia dijadikan sebagai museum Turki (Sani, 1998: 127).

Berlanjut setelah kejadian pengesahan penerapan sekular di atas, terjadilah kembali penghapusan berupa wewenang pengadilan-pengadilan agama dalam persoalan sipil dan membubarkan kementrian yayasan tawakal serta sekolah-sekolah agama. Sebenarnya tujuan utama pembaruan Turki adalah memisahkan Turki dari tradisi Arab-Asia yang telah mengakar pada masa sebelumya (Lenzowski, 1993: 78).

Sejak Turki Utsmani berganti menjadi Republik Turki dan dipimpin oleh Mustafa Kemal, Turki banyak mengalami pergeseran peradaban yang awalnya Arab-Asia menjadi budaya Barat-Eropa yang sifatnya sekularisme. Ada tiga bidang yang bisa dicermati dalam dorongan sekularisme yang merupakan unsur paling menonjol dari reformasi Kemalis. Pertama, adalah sekularisasi negara, pendidikan, dan hukum berupa serangan terhadap pusatpusat kekuatan tradisional ulama yang sudah melembaga. Kedua, adalah serangan terhadap simbol-simbol peradaban Eropa. Ketiga, adalah sekularisasi kehidupan sosial dan serangan terhadap Islam yang dianut rakyatnya (Zurcher, 2003: 71-78).

Unsur pertama telah dijelaskan pada paragraf sebelumnya, di mana nama-nama lembaga dan sistem yang berjalan sebelumnya diubah. Kemudian berlanjut pada unsur kedua, di mana semua simbol-simbol agama (Islam) dihapuskan di Turki. Seperti halnya, hari libur 
Nalar: Jurnal Peradaban dan Pemikiran Islam

Vol. 3, No. 1, Juni 2019

yang awalnya hari Jumat menjadi hari Minggu, dan lain sebagainya. Dalam hal ini umat muslim yang tinggal di Turki baru bergejolak melawan pemerintahan ketika Kemalis mulai menyentuh agama-sosialnya. Seperti halnya peniadaan hal-hal yang berbau keagamaan khususnya Islam seperti pakaian-pakaian Islam, tarekat, dan lain sebagainya (Tabrani, 2016: 138-142).

\section{Perjuangan Badiuzzaman Said Nursi dalam Mempertahankan Islam di Turki}

Sejak Turki dikuasai Mustafa Kemal Attaturk, Turki kehilangan jati diri Islam yang telah lama tertanam. Hal itu dikarenakan derasnya arus budaya Barat dan melemahnya nilainilai Islam. Terlebih ketika Partai Republik Turki sepenuhnya mengambil alih kekuasaan. Budaya Barat memengaruhi pemerintahan Mustafa Kemal Attaturk, sehingga sistem dan kebijakan-kebijakan Islam yang ada di Turki perlahan dihapuskan (Husaini, 2005: 272).

Ideologi liberal-sekularisme yang diusung Mustafa Kemal Attaturk ini kemudian mendapat perhatian dan dikawal perkembangannya oleh Badiuzzaman Said Nursi karena dinilai melemahkan fungsi Islam dalam kenegaraan. Dari pengertian ini, Mukti Ali (Ali, 1994: 133) berpendapat bahwa ketika kedua ideologi itu diterapkan, maka yang berkewajiban mengatur segala aspek materil dalam kehidupan rakyat adalah negara, sementara aspek spiritual dianggap sebagian dari agama.

Disaat seperti ini, Badiuzzaman Said Nursi berusaha membendung dengan usahausaha yang dilakukannya. Meski berkali-kali dibungkam seperti dipenjara, diasingkan, bahkan beberapa kali diracuni, Said Nursi tetap berkomitmen untuk tetap melestarikan Islam yang telah lama berkembag di Turki. Irmayanti (Irmayanti, 2017: 44-58) berpendapat bahwa Said Nursi melakukan tiga usaha strategis dalam membendung arus sekularisasi di Turki. Pertama yaitu dalam bidang pendidikan, yang kedua dalam bidang kemasyarakatan, dan usaha Said Nursi yang ketiga dalam bidang agama. Akan tetapi semua usaha strategis yang dilakukan bermuara pada satu sumber yang terdapat dalam risalab nur yang ditulis, dijadikan pidato, dan dijadikan surat-surat untuk masyarakat Turki.

Perihal ini karena risalah nur merupakan karya universal yang isinya memuat pembahasan pokok utama, di antaranya: Pertama, tentang upaya memafhumi agama melalui ilmu modern serta menyelidiki dasar-dasar kepercayaan menurut pembahasannya yang sesuai dengan pemikiran modern. Kedua, tentang eksistensi dan ketunggalan Allah Swt., malaikat, kitab suci, kerasulan, takdir, dan keadilan dalam hidup yang meliputi pemenuhan kewajiban dan berakhlak luhur. Ketiga, tentang hikmah wahyu dan pemikiran manusia tentang kefasihan alquran dan ilmu pengetahuan, alquran sebagai mukjizat Nabi Muhammad saw., dan beberapa jenis mukjizat lainnya. Keempat, menyajikan tentang hakikat hikmah dan nilai mi'raj yang dialami Rasulullah. Kelima, menyuguhkan tentang aspek-aspek ketunggalan Ilahi, manifestasi keesaan Allah pada alam semesta dan manusia, dan iman dalam hubungannya dengan kebahagiaan dan penderitaan. Keenam, pembahasan tentang hari kebangkitan dan akhirat (Irmayanti, 2017: 47).

Risalab nur tersebar di kalangan petani pedagang kecil, pengrajin, dan rakyat jelata. Dengan latar belakang membentuk individu muslim Turki yang kokoh pendirian, risalab nur banyak mendapat perhatian masyarakat. Usaha Said Nursi tidak sia-sia karena hingga saat ini, balaqah yang didirikan telah menjadi Gerakan Nurcu (Khamami, 2015: 3). Sejak dihapuskannya undangan-undang Islam berupa penghapusan semua simbol-simbol Islam seperti dihapuskannya tulisan Arab dan diwajibkannya menggunakan tulisan-tulisan latin secara keseluruhan. Semua tulisan dan bacaan-bacaan Arab dilarang, alquran semula bernaskah Arab diganti dengan tulisan latin Turki. Said Nursi melawan kebijakan ini dengan cara menyebarkan risalah nur. Dalam keadaan ini risalah nur berperan penting dalam menjaga 
Nalar: Jurnal Peradaban dan Pemikiran Islam

Vol. 3, No. 1, Juni 2019

naskah alquran dan huruf Arab tidak hilang dari peradaban Turki (Vahide, 2007: 216).

Selain itu, risalah nur juga berperan dalam menjaga kelangsungan tarekat yang pernah dihapus pemerintahan Mustafa Kemal Attaturk pada 1925 M. Bersama dengan amalan Hizb an-Nur, dan wirid Jawshan al-Khabir, risalah nur menggantikan peran penting kegiatan tarekat yang biasa dilakukan di zawiyah tarekat. risalah nur mengajak umat muslim agar senantiasa melantunkan zikir sekaligus tafakkur dan menggunakan akal serta hati (Salih, 2003: 148).

Sesuai dengan isi kandungan alquran dan hadis, risalah nur juga berperan dalam menjelaskan hakikat Iman untuk meningkatkan kesadaran umat beragama. Dalam menjelaskan kandungan risalah nur, Said Nursi secara jelas melawan budaya Barat dengan tidak membenarkan doktrin filsafat materialistik dan naturalistik. Said Nursi dalam penjelasannya lebih memilih dan mengedepankan metode tafakkur yang menekankan penggunaan majaz dan perbandingan untuk menjelaskan suatu problem.

Segala yang ditulis dan yang dikatakan Said Nursi terdapat dalam risalah nur. Dengan pelbagai cara, Said Nursi berupaya mendorong masyarakat agar sadar adanya Tuhan semesta alam. Serta membuang segala keraguan yang membelenggu yang dapat menjauhkan masyarakat Turki dari nilai-nilai Islam yang berusaha dilenyapkan pemerintahan Mustafa Kemal Attaturk (Sani, 1998: 120).

Sebagaimana yang dikatakannya ketika banyak orang memandang dan menganggap Said Nursi sebagai Syaikh dan sufi besar Turki. Said Nursi berkata, "Aku bukanlah syaikh tarekat dan saat ini bukan waktunya untuk mengikuti tata cara seperti yang diajarkan para syaikh tarekat sufi. Saat ini tidak lain waktunya untuk menyelamatkan iman" (Irmayanti, 2017: 46-47).

\section{Penutup}

Said Nursi adalah salah pemikir Islam yang paling cemerlang dengan berbagai prestasi, kepribadian, dan karakter hidupnya. Said Nursi merupakan tokoh penting dalam dunia Islam abad ke-20. Berkat perjuangannya dalam membendung arus radikalisasi budaya Barat secara terus menerus, Islam di Turki hingga saat ini dapat bertahan. Dengan cara yang sangat efektif dan luar biasa, Said Nursi sajikan kekuatan intelektual, moral, dan rohani Islam dalam bentuk ceramah di masjid tempat pengasingan dan tulisan risalab nur sebagai penjelas alquran yang disebarkan secara manual sehingga mampu memengaruhi umat Islam untuk tetap konsisten pada pendiriannya terhadap Islam.

Adapun sejarah penerapan sistem sekular pada masa pemerintahan Mustafa Kemal Attatur di Turki, merupakan peringatan agar umat muslim secara keseluruhan berhati-hati dalam mengkonsumsi budaya Barat meskipun budaya Barat lebih maju dari Islam. Hal ihwal ini karena tidak semua budaya Barat mengandung nilai positif bagi umat muslim khususnya. Sementara bagaimana baiknya sikap dan pemikiran yang harus kita terapkan dalam menjunjung perkembangan peradaban adalah sebagaimana yang ditawarkan oleh Said Nursi, yakni mengintegrasikan nilai-nilai positif antara budaya Barat dan Islam dalam bentuk apa pun. 
Nalar: Jurnal Peradaban dan Pemikiran Islam

Vol. 3, No. 1, Juni 2019

\section{Daftar Pustaka}

Ali, Mukti. 1994. Islam dan Sekularisme di Turki Modern, Jakarta: Djambatan.

Astuti, Puji. 2018. "Tasawnf Tanpa Tarekat: Kajian Terhadap Pemikiran Tasawuf Badiuzzaman Said Nursi”. Skirpsi diajukan pada Sekolah Tinggi Agama Islam Sunan Pandanaran.

El Shirazy, Habiburrahman. 2014. Api Taubid: Cahaya Keagungan Cinta sang Mujaddid, Jakarta: Republika.

Husaini, Adian. 2005. Wajah Peradaban Barat: Dari Hegomoni Kristen ke Dominasi Sekuler-Liberal, Jakarta: Gema Insani Press.

Irmayanti. 2017. "Bediuzzaman Said Nursi: Studi Tentang Peranannya Terbadap Perkembangan Islam Masa Pemerintahan Mustafa Kemal Attaturk.", Skripsi diajukan pada Fakultas Adab dan Humaniora Universitas Islam Negri Alauddin Makassar.

Khamami, Akhmad Rizqon. 2015. "Kontribusi Gerakan Nurcu dalam Kebangkitan Islam di Turki", dalam Islamica: Jurnal Studi Keislaman, Vol. 10, No. 1, September.

Lenczowski, George. 1993. Timur Tengah di Tengah Kancah Dunia, terj Asgar Bixby, Bandung: Sinar Baru Algensindo.

Mughni, Syafiq A. 1997. Sejarah Kebudayaan Islam di Turki, Jakarta: Logos.

Nasution, Harun. 1996. Pembaharuan dalam Islam, Jakarta: Bulan Bintang.

Salih, Ihsan Kasim. 2003 Badiuzzaman Said Nursi Nazrat al-'Ammah 'an Hayatibi wa Atsaribi, terj. Nabil Lubis, Said Nursi: Pemikir dan Sufi Besar Abad 20 Membebaskan Agama dan Dogmatisme dan Sekularisme, Jakarta: PT Raja Grafindo Persada.

Sani, Abdul. 1998. Lintasan Sejarah Pemikiran: Perkembangan Modern dalam Islam, Jakarta: Raja Grafindo Persada.

Tabrani. 2016. "Perubahan Ideologi Keislaman Turki", dalam Jurnal Edukasi, Vol. 2, No. 2.

Thohir, Ajid. 2009. Perkembangan Peradaban di Kawasan Dunia Islam: Melacak. Akar-akar Sejarah, Sosial, Politik, dan Budaya Umat Islam, Jakarta: Rajawali Pers.

Vahide, Sukran. 2007. Biografi Intelektual Badiuzzaman Said Nursi: Transformasi Dinasti Usmani Menjadi Republik Turki, terj. Sugeng Haryanto, Jakarta: Anatolia.

Zurcher, Erik J. 2003. Sejarah Modern Turki, Jakarta: Gramedia. 